\title{
Interaction Between Liquid Silver and Graphene-Coated SiC Substrate
}

\author{
Marta Homa, Natalia Sobczak, Jerzy J. Sobczak, Artur Kudyba, Grzegorz Bruzda, Rafał Nowak, Donatella Giuranno, \\ Katarzyna Pietrzak, and Marcin Chmielewski
}

(Submitted June 9, 2018; published online July 10, 2018)

\begin{abstract}
Wettability between liquid $\mathrm{Ag}$ and graphene-coated $\mathrm{SiC}$ single crystal has been investigated by dispensed drop method at $T=970{ }^{\circ} \mathrm{C}$ under vacuum accompanied with subsecond recording of the drop/substrate images (100 frames per second) by high-speed high-resolution CCD camera. Non-contact heating method coupled with capillary purification of the Ag drop procedure has been applied. Scanning electron microscopy combined with EDS analysis and scanning probe microscopy combined with Raman spectroscopy techniques has been utilized for microstructure and surface characterization of samples before and after high-temperature wetting tests. Immediately after its detachment from the capillary, the Ag drop showed non-wetting behavior $\left(\theta>90^{\circ}\right)$ forming a high contact angle of $\theta=114^{\circ}$. Surface characterization of the drop surface after wettability tests evidenced the presence of graphene and Si transferred from the substrate to the top of Ag drop. These findings suggest chemical interaction phenomena occurring at the interface. Locally, an intimate contact between liquid $\mathrm{Ag}$ and $\mathrm{SiC}$ substrate was allowed by the appearance of discontinuities in the graphene layer basically produced by thermomechanical stress. Local dissolution of carbon into liquid $\mathrm{Ag}$ and its reorganization (by segregation, nucleation and growth) as secondary graphene layer at the Ag surface was also observed.
\end{abstract}

Keywords $\mathrm{Ag} / \mathrm{graphene}, \mathrm{Ag} / \mathrm{SiC}$, dispensed drop, sessile drop method, wetting at high temperature

\section{Introduction}

The use of graphene $\left(\mathrm{C}_{\mathrm{Gn}}\right)$ as a reinforcement material in metal matrix composites (MMCs) raises hopes of scientists to obtain materials with outstanding functional properties such as high thermal conductivity coupled with low thermal expansion coefficient (Ref 1), particularly useful for aeronautical, aerospace and automobile industries (Ref 1). The group of metals considered potentially applicable as a matrix of graphenecontaining composite materials is $\mathrm{Al}, \mathrm{Cu}$ and $\mathrm{Ag}$ (Ref 1-4). With the exception of $\mathrm{Al}$ that easily forms aluminum carbide $\left(\mathrm{Al}_{4} \mathrm{C}_{3}\right)$ (Ref 2), $\mathrm{Cu}$ and $\mathrm{Ag}$ are non-reactive elements with respect to carbon. Moreover, carbon solubility in these metals at the liquid state is extremely low, showing $<0.01$ at.\% $\mathrm{C}$ in liquid $\mathrm{Cu}(\operatorname{Ref} 5)$ and $\sim 10^{-7}$ at.\% $\mathrm{C}$ in liquid $\mathrm{Ag}(\operatorname{Ref} 6)$.

It should be highlighted that the successful fabrication of Ag- and $\mathrm{Cu}$-matrix composites with carbon reinforcements by liquid-assisted processes remains highly uncertain, despite the fact that the most common technological problems related to

Marta Homa, Jerzy J. Sobczak, Artur Kudyba, Grzegorz Bruzda, and Rafal Nowak, Foundry Research Institute, 73 Zakopianska St., 30-418 Krakow, Poland; Natalia Sobczak, Foundry Research Institute, 73 Zakopianska St., 30-418 Krakow, Poland; and Institute of Precision Mechanics, 3 Duchnicka St., 01-796 Warsaw, Poland; Donatella Giuranno, Institute of Condensed Matter Chemistry and Technologies for Energy, National Research Council of Italy, 6 De Marini St., 16149 Genoa, Italy; and Katarzyna Pietrzak and Marcin Chmielewski, Institute of Electronic Materials Technology, 133 Wolczynska St., 01-919 Warsaw, Poland. Contact e-mail: marta.homa@iod.krakow.pl. non-uniform distribution of the reinforcing phase in the metal matrix or weak bonding between the metal matrix and the reinforcement (due to lack of wetting and weak adhesion) have been largely solved using nanostructured carbon reinforcement having similar surface structure to graphene such as nanotubes. On the contrary, a practical solution to obtain tailored MMCs with graphene as reinforcing phase is still missing. The main growth-limiting factor for this technology is essentially due to the graphene structure, which is a $2 \mathrm{D}$ material one atom thick (Ref 3). It makes difficult to apply the procedures commonly used for improving wettability and bonding between dissimilar materials, e.g., by the addition of carbide-forming elements like $\mathrm{Cr}$ or $\mathrm{Ti}$ since the corresponding chemical reactions lead to the devastation or even complete disruption of graphene. Currently, scarce information is available in the literature on the possibility of graphene formation involving molten metal, e.g., $\mathrm{Cu}$ (Ref 7-9), Ga-Cu (Ref 10), Ga (Ref 11) or Ni (Ref 8). There are several reports on wetting characteristics of graphene with nonmetallic liquids (water, organic solutions) measured at room temperature and showing unusual phenomenon named "wetting transparency" (Ref 12, 13), namely graphene coatings do not significantly modify the intrinsic wetting behavior at the interface and, specifically, for surface-water couples, the interactions are dominated by van der Waals forces. Despite the technological interest, only two reports are available in the literature on wetting behavior of different liquid metals [Sn (Ref 14), Cu (Ref 15)] on graphene. The preliminary studies performed by the authors at the Foundry Research Institute with liquid $\mathrm{Sn}$ on graphene-coated $\mathrm{Cu}$ substrates (Ref 14) did not give clear evidences of wetting transparency behavior in the $\mathrm{Sn} /$ $\mathrm{C}_{\mathrm{Gn}} / \mathrm{Cu}$ system since, despite significant suppression of wetting kinetics, a strong chemical interaction accompanied by the formation of intermetallic phases $\left(\mathrm{Cu}_{3} \mathrm{Sn}, \mathrm{Cu}_{5} \mathrm{Sn}_{6}\right)$ at the interface were observed. Based on structural observations, it was concluded in (Ref 14) that Sn-transfer phenomenon 
occurred through discontinuities in the graphene layer, most probably formed during high-temperature test (e.g., due to thermomechanical stresses and carbon rearrangement in the graphene layer). Preliminary conclusions on wetting transparency behaviors observed on $\mathrm{Cu} / \mathrm{C}_{\mathrm{Gn}} / \mathrm{SiC}$ system were recently reported in (Ref 15$)$. In particular, comparable wetting behavior was observed in $\mathrm{Cu} / \mathrm{C}_{\mathrm{Gn}} / \mathrm{SiC}$ and $\mathrm{Cu} / \mathrm{SiC}$ systems. Moreover, performing few attempts to detach the liquid $\mathrm{Cu}$ drop from both the graphene-coated $\mathrm{SiC}$ and graphene-free $\mathrm{SiC}$ substrates by rising up the dispensing graphite capillary, both the $\mathrm{Cu} / \mathrm{C}_{\mathrm{Gn}} / \mathrm{SiC}$ and $\mathrm{Cu} / \mathrm{SiC}$ systems displayed the same adhesive response. On the contrary, the liquid $\mathrm{Cu}$ drop/graphite shown a weak adhesion and the liquid $\mathrm{Cu}$ drop was easily removed, confirming that, the interfacial phenomena, in terms of dissolution and reactivity at the interface $\mathrm{Cu} / \mathrm{C}$ are less pronounced than $\mathrm{Cu} / \mathrm{Si}$ and $\mathrm{Cu} / \mathrm{SiC}$ ones. In addition, by the surface characterization performed by SEM and Raman spectroscopy techniques, chemical etching and fragmentation of the graphene layer at the interface were revealed as well as mass transfer through the interface and changes in the structure and chemistry of the drops and the corresponding interfaces formed. Collecting all the outcomes, it is possible to conclude that the presence of graphene layer at the $\mathrm{SiC}$ substrate at least seems limiting the chemical interaction between liquid $\mathrm{Cu}$ drop and $\mathrm{SiC}$ substrate.

This time we moved our interest in high-temperature interaction phenomena occurring between liquid $\mathrm{Ag}$ and graphene-coated SiC single crystal substrate. The evolution of the phenomena has been recorded with a subsecond rate using the same testing procedure and experimental facility previously used for the $\mathrm{Sn} / \mathrm{C}_{\mathrm{Gn}} / \mathrm{Cu}$ (Ref 14) and $\mathrm{Cu} / \mathrm{C}_{\mathrm{Gn}} / \mathrm{SiC}$ (Ref 15) systems.

\section{Experimental}

\subsection{Materials}

The materials used were Ag $(99.9999 \%)$ with class purity of $6 \mathrm{~N}$ from ESPI metals $(\mathrm{Pb}<0.20,0.10 \mathrm{Ni}, 0.19 \mathrm{Cu}, 0.46 \mathrm{Pd}$, $0.14 \mathrm{Fe}$, in $\mathrm{ppm}$ ) and graphene-coated $\mathrm{SiC}$ single crystal produced by the Institute of Electronic Materials Technology (Warsaw, Poland). Graphene $\left(\mathrm{C}_{\mathrm{Gn}}\right)$ was grown on the $6 \mathrm{H}-\mathrm{SiC}$ (0001) single crystal substrate $\left(\mathrm{SiC}^{\mathrm{sc}}\right)$ by chemical vapor deposition (CVD) as detailed elsewhere (Ref 16). After graphene deposition, the $\mathrm{C}_{\mathrm{Gn}} / \mathrm{SiC}^{\mathrm{sc}}$ sample was preserved in a sealed container filled with argon.

\subsection{Methods}

The high-temperature wetting behavior of liquid $\mathrm{Ag}$ in contact with graphene-coated $\mathrm{SiC}^{\mathrm{sc}}$ was examined by the sessile drop method (Ref 15). The test was performed at $T=970{ }^{\circ} \mathrm{C}$ under a vacuum mbar using experimental complex described in details in (Ref 17) by improved dispensed drop technique (i.e., non-contact heating) accompanied with capillary purification (cp). Such method of purification allows to avoid the effects of a primary oxide film at the surface of a metal sample as well as heating history of an alloy/substrate couple on its wetting behavior (Ref 18).

Prior the loading into the vacuum chamber, the surface of Ag sample was mechanically and ultrasonically cleaned in isopropanol and placed inside an alumina capillary positioned above the substrate. The graphene-coated SiC substrate was placed on an alumina support located inside a tantalum-resistant heater.

After gas evacuation, the experimental chamber was vacuumed up to $p=1.78 \times 10^{-6}$ mbar by means of a turbomolecular pump, and the $\mathrm{C}_{\mathrm{Gn}} / \mathrm{SiC}^{\mathrm{sc}}$ substrate and $\mathrm{Ag}$ were noncontact heated up to a test temperature of $T=970{ }^{\circ} \mathrm{C}$ with a heating rate of $10{ }^{\circ} \mathrm{C} / \mathrm{min}$. When the experimental temperature was reached, the Ag drop was squeezed through a hole of the capillary and gently deposited on the substrate as shown in Fig. 1.

Within the isothermal wettability test at $T=970{ }^{\circ} \mathrm{C}$, the total pressure in the vacuum chamber was kept constant $\left(p=2.79 \times 10^{-5} \mathrm{mbar}\right)$. After holding at the test temperature, the systems were cooled down at room temperature with a cooling rate of $10{ }^{\circ} \mathrm{C} / \mathrm{min}$.

During the wetting test, the images of the couple were recorded by means of high-speed high-resolution camera MC1310 with a rate of 100 frames per second. The collected images were used to estimate the contact angle values (either manually or by calculation with a use of a special software ASTRA2 [ICMATE-CNR, Italy (Ref 19, 20)] as well as for making a movie of high-temperature test performed (SUPPLEMENT \#1). The software enables determination of both the left and right contact angle values, even the size parameters of the drop, by an automatic image analysis with systematic assessed uncertainty of the contact angle less than $\pm 2^{\circ}$.

A careful surface and microstructural characterization was performed on both the starting materials and the solidified sessile drop $\mathrm{Ag} / \mathrm{C}_{\mathrm{Gn}} / \mathrm{SiC}^{\mathrm{sc}}$ couple using the following techniques:

1. Scanning Probe Microscopy (SPM) combined with Raman spectroscopy using NTEGRA SPECTRA system (NT-MDT Europe). The Raman spectra were taken under ambient conditions using a diode-pumped solid-state laser with a wavelength of $473 \mathrm{~nm}$. The incident laser power laser was $50 \mathrm{~mW}$, the spot size $\sim 1 \mu \mathrm{m}$ in diameter and the exposure time $300 \mathrm{~s}$.

2. Scanning electron microscopy (SEM) using TM3000 HITACHI device equipped with energy-dispersive $\mathrm{x}$-ray spectroscopy (EDS) analyzer.

\section{Results}

In Fig. 2a and b, the most representative results of SPM and Raman spectroscopy examinations of the $\mathrm{C}_{\mathrm{Gn}} / \mathrm{SiC}^{\mathrm{sc}}$ substrate surface performed prior to the wettability test are shown. The SPM image (Fig. 2a) displays the SiC surface with terraces, whereas Raman spectrum (Fig. 2b) shows the typical features of double-layer graphene produced on the $\mathrm{SiC}$ substrate, with narrow $\mathrm{G}\left(1589 \mathrm{~cm}^{-1}\right)$ and 2D peaks $\left(2728 \mathrm{~cm}^{-1}\right)(\operatorname{Ref} 21,22)$.

The analysis of images collected from the test (Fig. 3a-h) revealed that after the squeezing of the $\mathrm{Ag}$ drop and its gentle deposition on the $\mathrm{C}_{\mathrm{Gn}} / \mathrm{SiC}^{\mathrm{sc}}$ substrate, a slight drop movement to the left edge of the substrate was provoked by the further rising of the capillary (Fig. 3f and g). Finally, the drop achieved a stable spherical shape with corresponding contact angle of $\theta=114^{\circ}$ at a time of $t=7 \times 10^{-2} \mathrm{~s}$. Isothermal condition for $11 \mathrm{~min}$ did not affect the contact angle value as well as the drop shape and its position (Fig. 3h). 

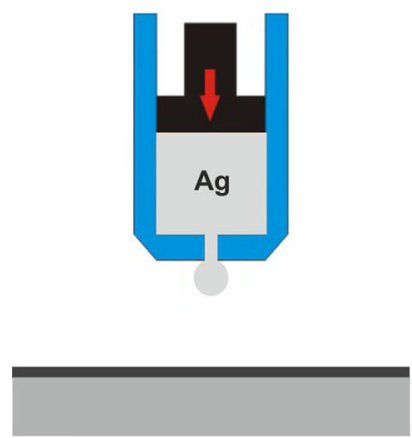

(a)

graphene

$\mathrm{SiC}^{\mathrm{sc}}$
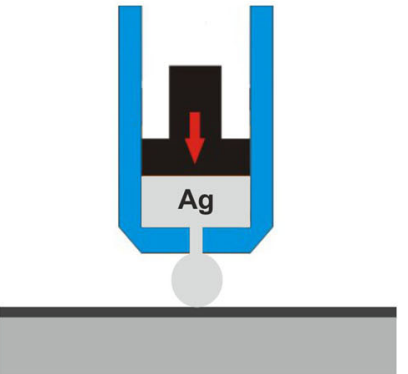

(b)

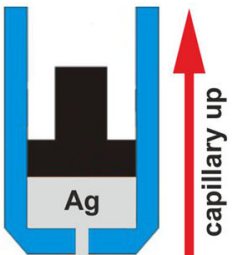

(c)

Fig. 1 Procedure of the sessile drop wettability test of $\mathrm{Ag}$ on $\mathrm{C}_{\mathrm{Gn}} / \mathrm{SiC}^{\text {sc }}$ substrate by dispensed technique: (a) non-contact heating of $\mathrm{Ag}$ and $\mathrm{C}_{\mathrm{Gn}} / \mathrm{SiC}$ followed by squeezing the liquid $\mathrm{Ag}$ through a hole; (b) gentle deposition of Ag drop; (c) raising up of the capillary
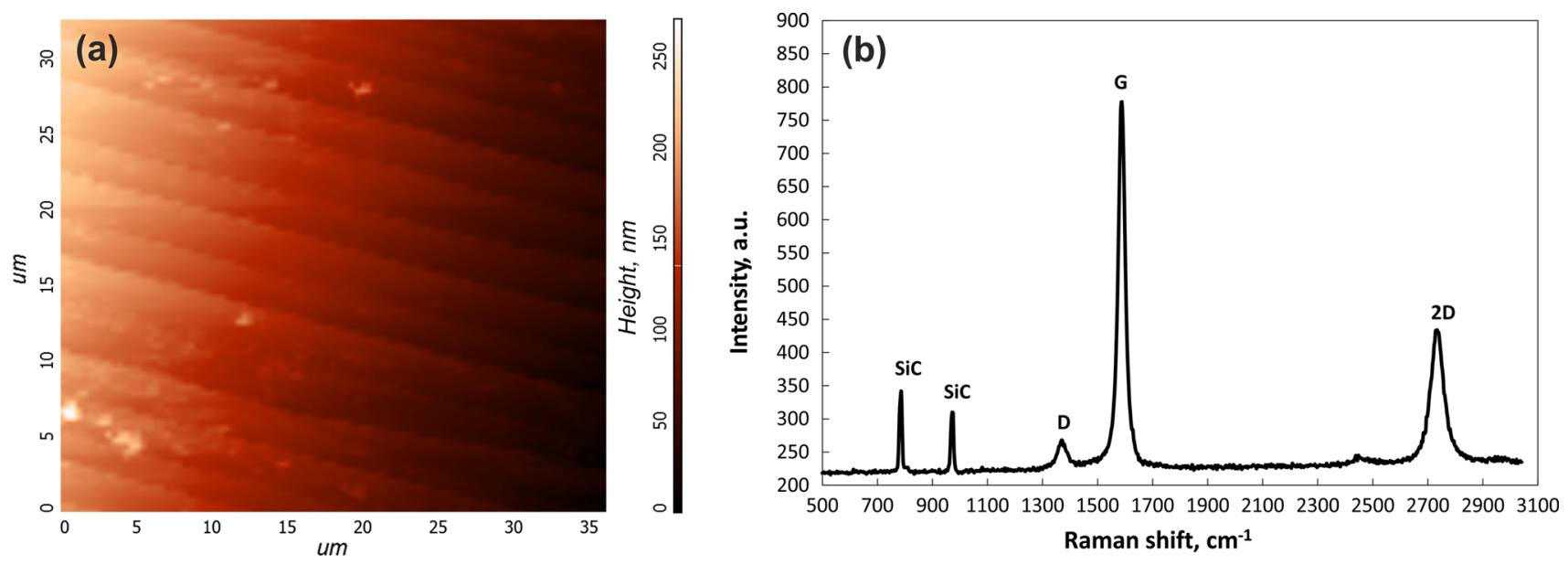

Fig. 2 Surface characterization of graphene layer grown up on 6H-SiC(0001): (a) SPM image; (b) Raman spectrum
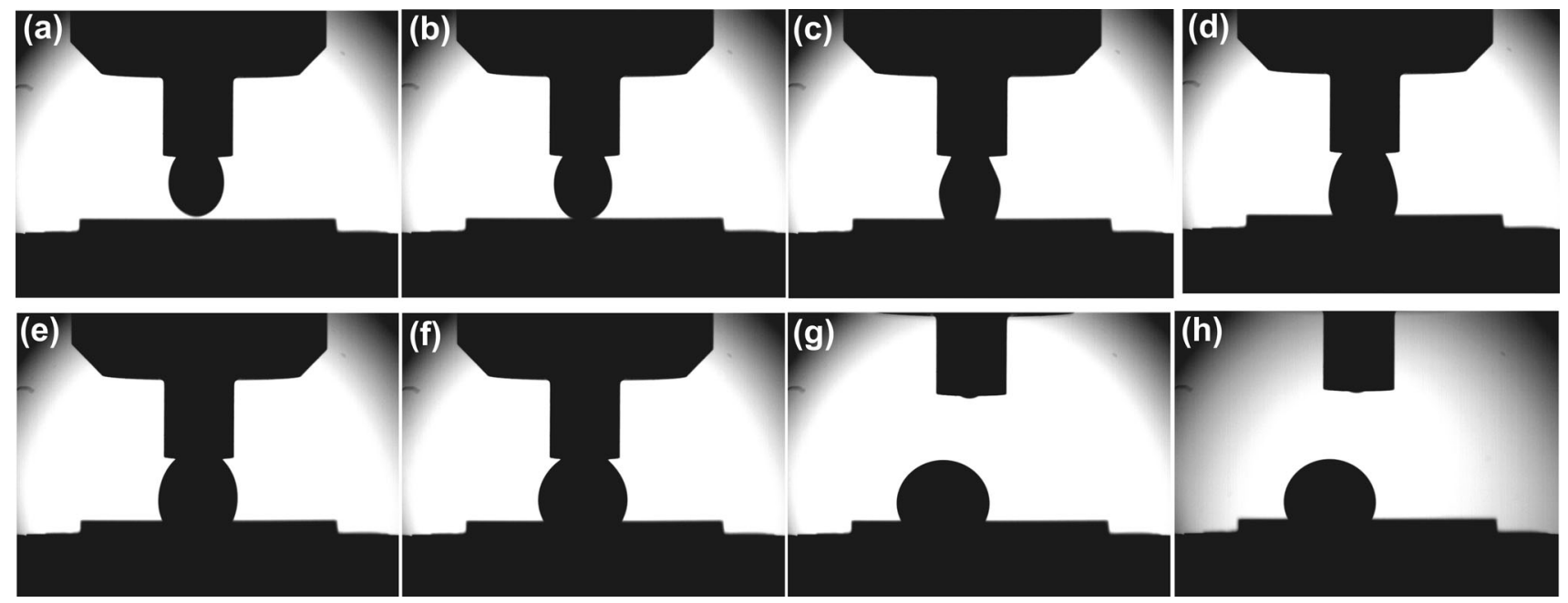

Fig. 3 Images of the most representative stages of the sessile drop test: (a, b) Ag dropping from a capillary; (c-f) deposition of Ag drop on the substrate $(t=0 \mathrm{~s})$; $(\mathrm{g})$ detachment of $\mathrm{Ag}$ drop from the capillary accompanied with a drop movement $\left(t=7 \times 10^{-2} \mathrm{~s}\right)$; (h) Ag drop under isothermal condition at $T=970{ }^{\circ} \mathrm{C}(t=11 \mathrm{~min})$ 

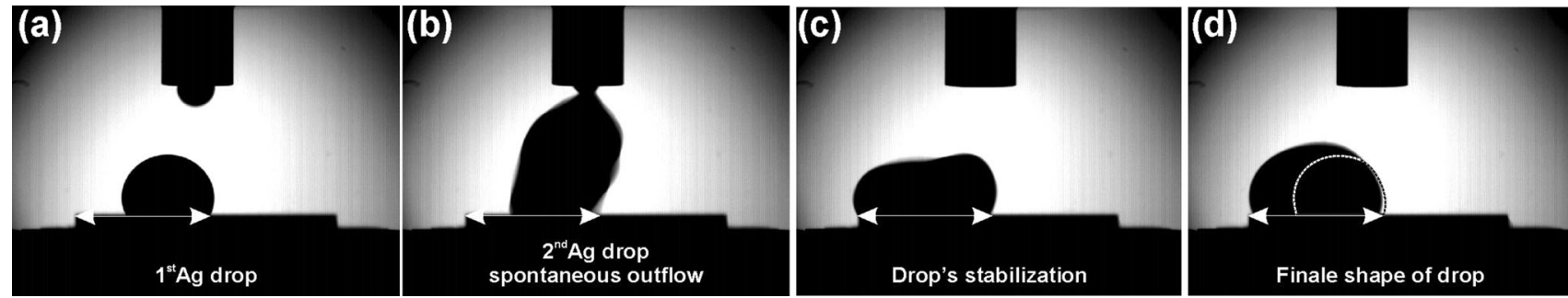

Fig. 4 Images of $\mathrm{Ag}$ drop during spontaneous squeezing liquid metal through the capillary: (a) the position of the first Ag drop on the substrate, (b) spontaneous dropping of the second $\mathrm{Ag}$ drop at the $t=12$ min of the test, (c) stabilization of $\mathrm{Ag}$ drop, (d) drop shape at equilibrium
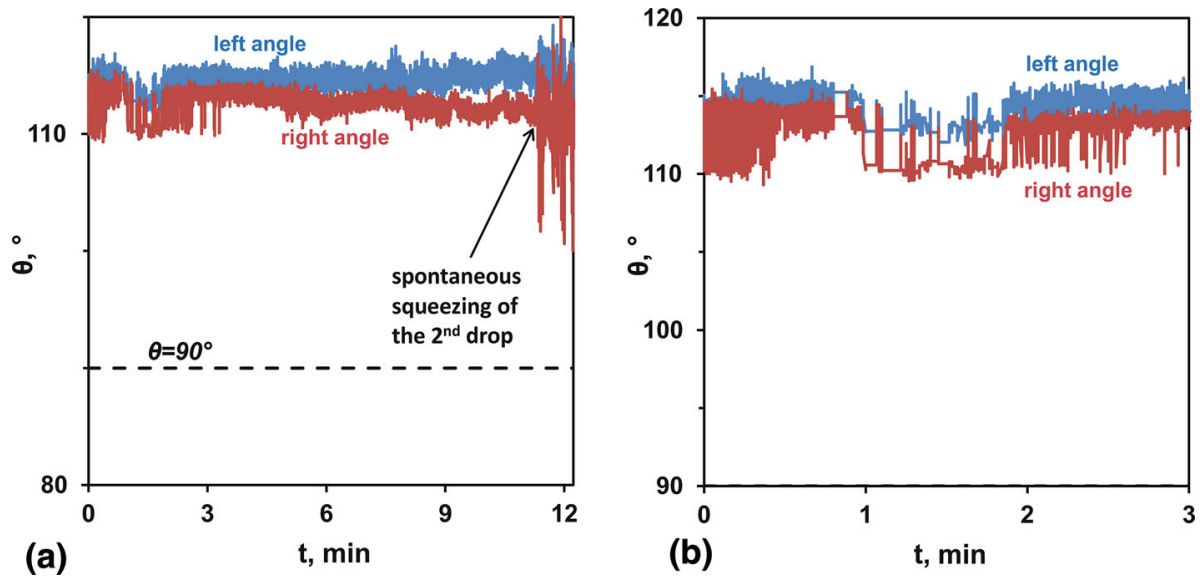

Fig. 5 Contact angle values of liquid $\mathrm{Ag}$ on $\mathrm{C}_{\mathrm{Gn}} / \mathrm{SiC}^{\mathrm{sc}}$ system as a function of time: (a) for $t=0-12$ min, (b )the magnified part of (a) for $t=0-3 \min$

At $t=12$ min of the test, a spontaneous squeezing and dropping of the second $\mathrm{Ag}$ drop on the first drop occurred increasing as a consequence the drop volume (Fig. 4) and the test was stopped. A detailed analysis of the images collected from the spontaneous dropping of the second Ag drop (Fig. 4ad) showed that the drop slightly changed its position (Fig. 4d).

Figure 5 shows the evolution of contact angle $(\theta)$ as a function of time within the wettability test of the $\mathrm{Ag} / \mathrm{C}_{\mathrm{Gn}} / \mathrm{SiC}{ }^{\mathrm{sc}}$ couple. Immediately after squeezing through the ceramic capillary and deposition on the $\mathrm{C}_{\mathrm{Gn}} / \mathrm{SiC}$ substrate, the first Ag drop does not wet it $\left(\theta>90^{\circ}\right)$ showing a contact angle of $\theta=114^{\circ}$ (Fig. 5a). After approximatively $1 \mathrm{~min}$, a scatter in the contact angle values is observed. It was related to an abnormal kinetics (Fig. 5b) with a decrease in the contact angle to a value of $\theta=110^{\circ}$, which during the second minute of the test, rises again up to a value of $\theta \sim 114^{\circ}$. Holding the couple for $11 \mathrm{~min}$, the value of the contact angle does not change (Fig. 5a). The scatter of data is observed at the $t=12 \mathrm{~min}$ of the test and is owing to the spontaneous squeezing of the second Ag drop.

By visual observations of the $\mathrm{Ag} / \mathrm{C}_{\mathrm{Gn}} / \mathrm{SiC}^{\mathrm{sc}}$ couple after wettability test (Fig. 6), the Ag drop displays a spherical shape. At the top drop surface, a gray area was observed (Fig. 6a), which was mostly localized on the side view of the drop. SEM examination of the mentioned gray area revealed its wrinkled structure on smooth Ag drop surface (Fig. 6a, b). The Ag drop surface was covered by small dark precipitates while on the wrinkled area, the amount of dark precipitate was bigger (Fig. 6b). By chemical analysis of these precipitates, the presence of $\mathrm{C}$ and traces of $\mathrm{Si}$ was revealed (Fig. 6c).
As a result of weak mechanical push, the drop was detached from the substrate (Fig. 7) and the presence of an oval shadow was revealed on the $\mathrm{C}_{\mathrm{Gn}} / \mathrm{SiC}$ surface (Fig. 7a). Visual observations at the bottom of the drop showed small gray light spot, of which SEM analysis at $100 \times$ magnification has revealed its triangular shape and an area covered by numerous craters of oval shape and various sizes (Fig. 7b), as revealed also by SPM examination (Fig. 7d). At a magnification of $500 \times$, it was found that the boundary between smooth area and area covered by oval voids shows a net contour (Fig. 7c).

The detachment of the Ag drop from the substrate gave the opportunity to perform carefully analyses at the surfaces by Raman spectroscopy, spot analyses both at the Ag drop surface from bottom side and at the exposed substrate surface (Fig. 8). Based on the analysis of the images recorded during the wetting experiment (Fig. 8a and b), two contact areas of the drop with the substrate surface were detected: named area I at the site of the first $\mathrm{Ag}$ drop deposition on the graphene-coated surface $(t=0 \mathrm{~s})$ and area II formed by the changed position of the first Ag drop $\left(t=1 \times 10^{-2} \mathrm{~s}\right)$ (Fig. 8c). Moreover, three subareas were identified: subarea 5 , which is the place of initial contact of the first Ag drop with the substrate surface, subarea 4, which is the common site for area I and area II, and subarea 3, which corresponds to the contact of the first drop with the surface after the change of drop position and also the place where the second Ag drop was squeezed spontaneously. The presence of graphene in wrinkled region was detected by Raman spectra taken from two spots at the surface of the Ag drop (Fig. 8d). Point 1 shows the typical spectrum of graphene layer, with narrow $\mathrm{G}\left(1598 \mathrm{~cm}^{-1}\right)$ and 2D peaks $\left(2735 \mathrm{~cm}^{-1}\right)$ (Ref 21). 

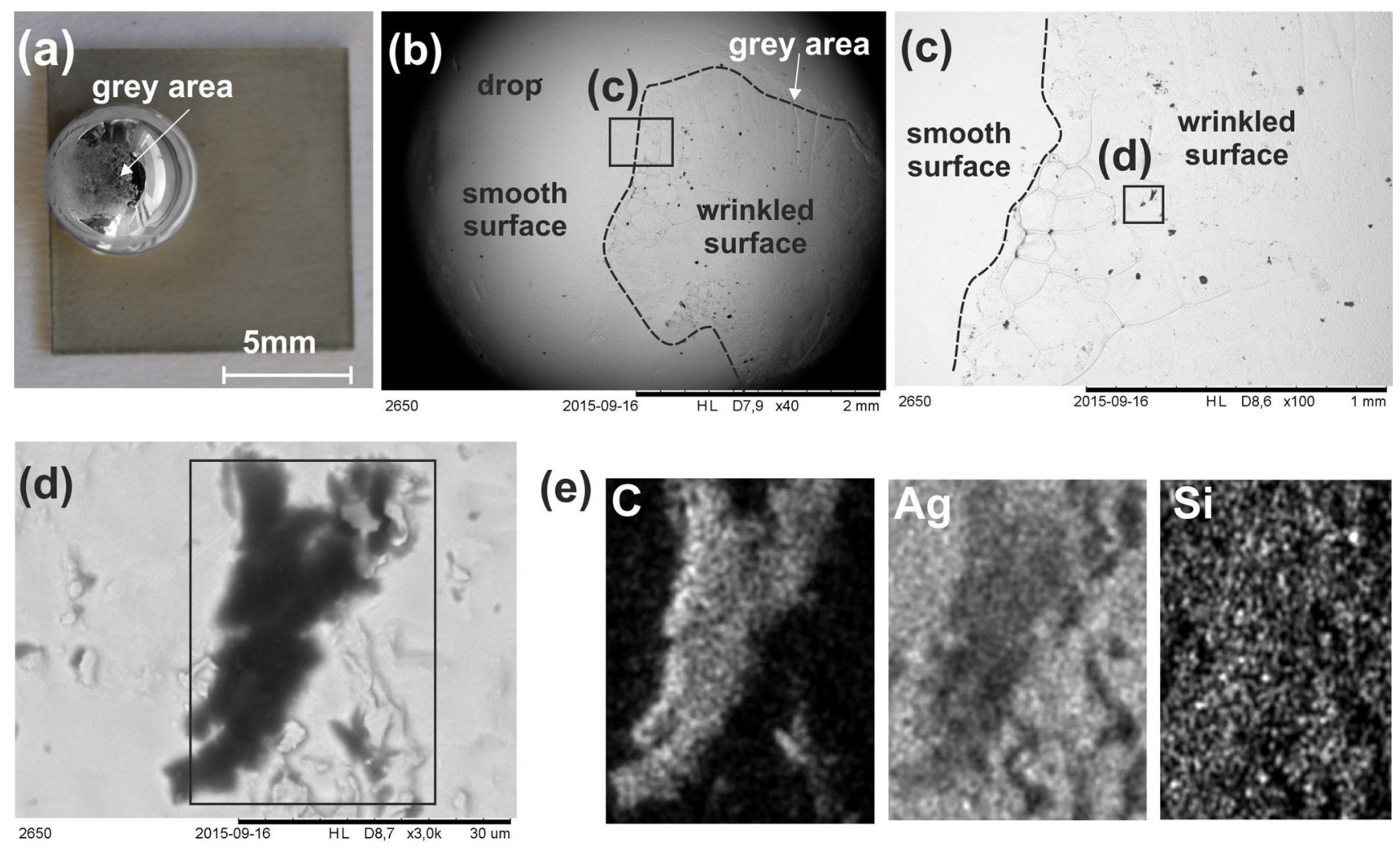

Fig. 6 Observations at the top of the solidified sessile drop: (a) photo; (b) SEM image from top surface of the drop with marked area (c); (c) SEM image from the observed gray region with marked area (d); (d) SEM image of dark precipitates with marked area (e); (e) mapping of Ag, $\mathrm{C}$ and $\mathrm{Si}$ in marked area in (d)

The presence of the D peak (about $1373 \mathrm{~cm}^{-1}$ ) indicates the defects in the graphene layer. The ratio of peak $\mathrm{I}_{2 \mathrm{D}} / \mathrm{I}_{\mathrm{G}}$ in spectra (1) is 0.9 that designates bilayer graphene (Ref 22). On the contrary, at the bottom of the Ag drop, the presence of the graphene layer was not detected.

From the analysis of the Raman spectra obtained at spots 3, 4, 5 on the substrate (Fig. 8e) one may conclude that in the area of the first contact between the Ag drop and the substrate (point $5)$, the intensity of the characteristic peak of $\mathrm{SiC}(\sim 1700$ $\left.2000 \mathrm{~cm}^{-1}\right)$ increases while there is not peak 2D $\left(\sim 2635 \mathrm{~cm}^{-1}\right)$, which is instead present in the spectrum formed in the common site of area I and area II (point 4), as well as in the spectrum taken from point 3 (contact of the first Ag drop with the substrate surface after capillary moving). In all spectra, a peak $\mathrm{G}\left(\sim 1680 \mathrm{~cm}^{-1}\right)$ is present.

\section{Discussion}

The results of wettability test of the $\mathrm{Ag} / \mathrm{C}_{\mathrm{Gn}} / \mathrm{SiC} \mathrm{C}^{\mathrm{sc}}$ couple are summarized in Table 1 and compared with previous studies of wetting characteristics of liquid $\mathrm{Ag}$ in contact with different substrates, i.e., glass-like carbon $\left(\mathrm{C}_{\mathrm{glc}}\right)$ (Ref 23,24$)$, graphite $\left(\mathrm{C}_{\mathrm{gr}}\right)$ (Ref 24-27), diamond $\left(\mathrm{C}_{\mathrm{d}}\right)$ (Ref 28$)$, SiC single crystal $\left(\mathrm{SiC}^{\mathrm{sc}}\right)$, polycrystalline $\mathrm{SiC}\left(\mathrm{SiC}^{\mathrm{pc}}\right)(\mathrm{Ref} 29,30)$ and $\mathrm{SiO}_{2}(\mathrm{Ref}$ $31)$.

The contact angle of $\mathrm{Ag} / \mathrm{C}_{\mathrm{glc}}$ system at two temperatures $T=970{ }^{\circ} \mathrm{C}$ and $T=1000{ }^{\circ} \mathrm{C}$ is $\theta=106^{\circ}$ and $\theta=117^{\circ}$, respectively (Table 1 data "Cglc") (Ref 23, 24), and they are in a good agreement with the data obtained in this work (for both the first and second drop of $\mathrm{Ag} 114^{\circ}$ and $113^{\circ}$ ) (Table 1 data "CGn/SiCsc").

Surveying the literature data, the wetting characteristics of $\mathrm{Ag} / \mathrm{C}$ system depend on the type of carbon substrates (amorphous, mono or polycrystalline) as well as on the testing conditions thus showing a large scattering of contact angle value from formed $124^{\circ}$ to $157^{\circ}$ (Ref 24-27) (Table 1 data "Cgr"). The effect of substrate orientation on the wettability in the $\mathrm{Ag} / \mathrm{C}$ system was already observed in the case of diamond substrate. Under the same experimental conditions, the contact angle values formed by liquid $\mathrm{Ag}$ on (111) $\mathrm{C}_{\mathrm{d}}$ and on (110) $\mathrm{C}_{\mathrm{d}}$ were $\theta=147^{\circ}$ and $\theta=103^{\circ}$, respectively (Ref 28) (Table 1 data "Cd").

On pure $\mathrm{SiC}$ substrate, the contact angle value of liquid $\mathrm{Ag}$ is higher than those on graphite and diamond: $\theta=145^{\circ}-148^{\circ}$ on polycrystalline $\mathrm{SiC}$ and $\theta=65^{\circ}$ on single crystal $\mathrm{SiC}$ (Table 1 data "CSiC") (Ref 30). Such different values obtained on single crystal $\mathrm{SiC}$ (Table 1 data "CSiC") are owing to the presence of surface native oxide $\left(\mathrm{SiO}_{2}\right)$ and to the reaction occurred between the molten $\mathrm{Ag}$ and the substrate giving as reaction product at the interface a few nanometers thicker layer of graphite (Ref 32). Kalogeropoulou et al. (Ref 30) demonstrated that the contact angle of $145^{\circ}$ measured for the $\mathrm{Ag} / \mathrm{SiC}$ system at $T=1100{ }^{\circ} \mathrm{C}$ in fact corresponds to the $\mathrm{Ag} / \mathrm{C}_{\mathrm{gr}}$ system due to dissolution of $\mathrm{Si}$ in liquid $\mathrm{Ag}$ accompanied with the release of carbon at the interface. Similar contact angle value was measured for $\mathrm{Ag} / \mathrm{SiO}_{2}$ couple (Ref 31) (Table 1 data " $\mathrm{CSiO}_{2}$ "). Further holding the system at the test temperature caused decreasing of contact angle value $\left(\theta=120^{\circ}\right)$ due to the deoxidation of the $\mathrm{SiC}$ substrate (Ref 32 ) by the following reaction: 

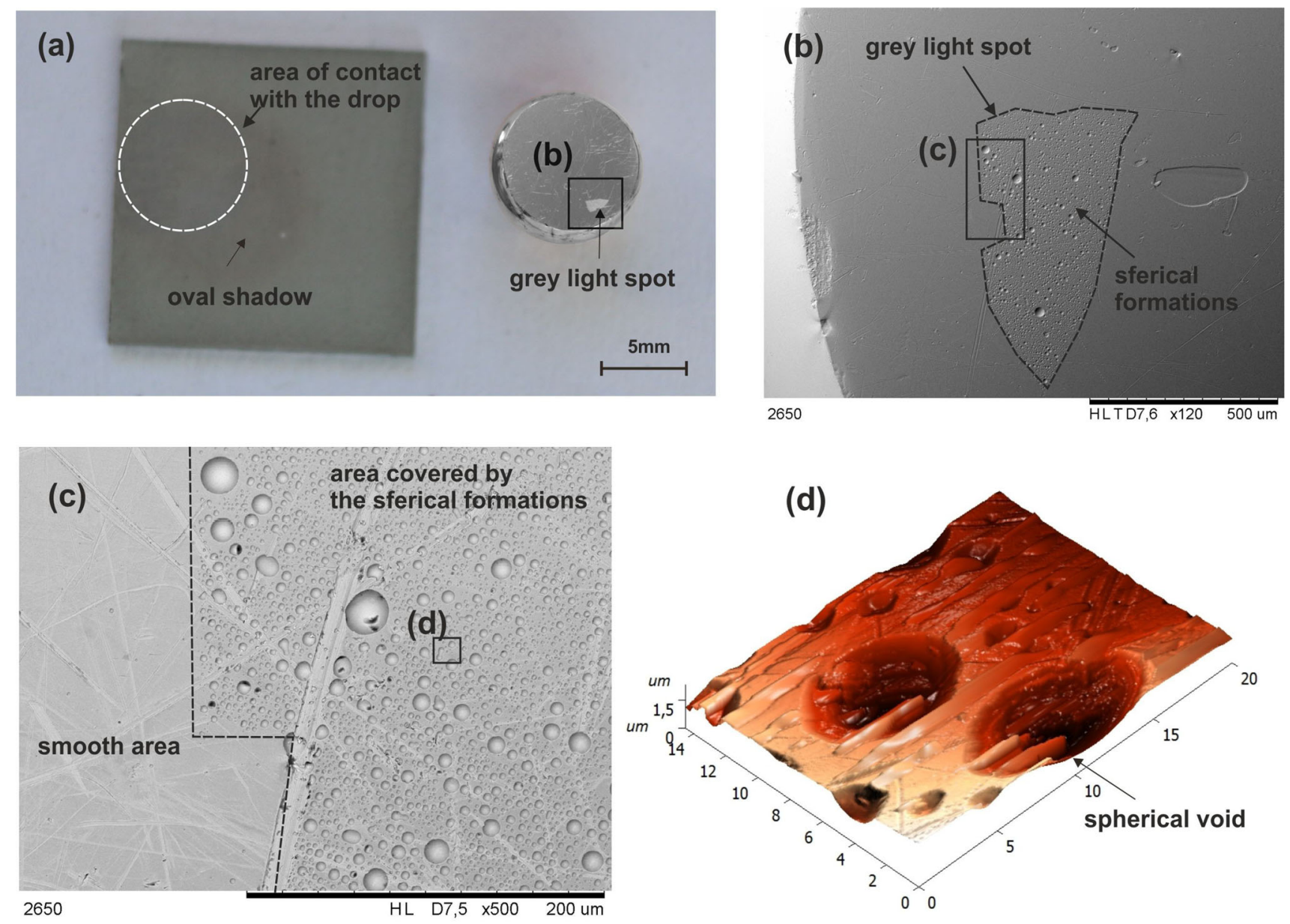

Fig. 7 Observations of the solidified sessile drop sample: (a) photo with marked area at the bottom of the drop (b); (b) SEM image of the gray bright spot with marked area of oval voids (c); (c) SEM image of the boundary between the area covered by the spherical formations and the smooth region with marked area (c); area covered by the spherical voids (a); SPM image of spherical voids microstructure (d)

$2 \mathrm{SiO}_{2(\mathrm{~s})}+\mathrm{SiC}_{(\mathrm{s})} \rightarrow 3 \mathrm{SiO} \uparrow+\mathrm{CO} \uparrow$

Moreover, increasing the temperature up to $T=1200^{\circ} \mathrm{C}$, a further decrease in the contact angle was observed with the final value of $\theta=66^{\circ}$. This value was obtained for silica-free $\mathrm{SiC}$ substrate, and it was associated with the reaction between $\mathrm{Ag}$ and $\mathrm{SiC}$ leading to the formation of graphite (Ref 32):

$\mathrm{SiC}_{(\mathrm{s})} \rightarrow(\mathrm{Si})+\mathrm{C}_{\mathrm{gr}}$

These findings suggest that freshly formed Si dissolves in liquid $\mathrm{Ag}$, and this process, i.e., dissolutive wetting is responsible for wettability improvement in the $\mathrm{Ag} / \mathrm{SiC}$ system.

To determine the influence of gas released from the substrate on the behavior (movement) of the first Ag drop, a detailed analysis of surrounding atmosphere was done by real-time records of the residual gas analyzer (Table 2).

As shown in Table 2, at room temperature under a vacuum of $p_{\text {total }}=1.78 \times 10^{-4} \mathrm{~Pa}$, low amounts of $\mathrm{H}_{2} \mathrm{O}$ and $\mathrm{H}_{2}$ were detected inside the vacuum chamber (Table 2 data " $25^{*}$ "). During heating up to $T=200{ }^{\circ} \mathrm{C}$, only small gasification from the $\mathrm{C}_{\mathrm{Gn}} / \mathrm{SiC}^{\mathrm{sc}}$ substrate was detected (Table 2 data " 200 "). However, increasing the temperature up to $T=970{ }^{\circ} \mathrm{C}$, an increase in $\mathrm{CO}_{2}, \mathrm{CO}, \mathrm{C}, \mathrm{H}_{2} \mathrm{O}$ and $\mathrm{H}_{2}$ concentrations in the surrounding atmosphere was revealed by the residual gas analyzer (Table 2 data " 970 "). Consequently, an increase in the total pressure up to a value of $p_{\text {total }}=2.96 \times 10^{-3} \mathrm{~Pa}$ was observed inside the chamber. At the squeezing of the first drop from the capillary $(t=0 \mathrm{~s})$, a release of $\mathrm{CO}_{2}$ was detected (Table 2 data " 1000 "). Since during the dropping of the second drop and within the isothermal conditions (12 $\mathrm{min})$ as well, no any further increase in $\mathrm{CO}_{2}$ concentration inside the chamber was detected (Table 2 data " 1000 " " and data " $1000^{2}$," respectively), we may conclude that the gas release from the $\mathrm{C}_{\mathrm{Gn}} / \mathrm{SiC}^{\mathrm{sc}}$ sample contributed to the movement of the first Ag drop.

Furthermore, the change in the position of the first Ag drop is accompanied with the increase in the amount of released $\mathrm{CO}_{2}$. It indicates that a fragment of uncovered (graphene-free) $\mathrm{SiC}$ substrate was exposed due to the displacement of Ag drop. The formation of $\mathrm{CO}_{2}$ is most likely associated with the interaction of revealed pristine $\mathrm{SiC}$ surface with oxygen dissolved in the Ag drop (Ref 33):

$\mathrm{Ag}+6 \mathrm{O}+2 \mathrm{SiC} \rightarrow 2 \mathrm{CO}_{2} \uparrow+\mathrm{Ag}+\mathrm{Si}+\mathrm{SiO}_{2}$

The presence of a triangular area of voids at the bottom of the solidified drop generated by the gas bubbles has confirmed that in this area with the exposed surface of $\mathrm{SiC}$ not coated by graphene, liquid $\mathrm{Ag}$ with a certain amount of dissolved oxygen had an intimate contact with pure $\mathrm{SiC}$. 

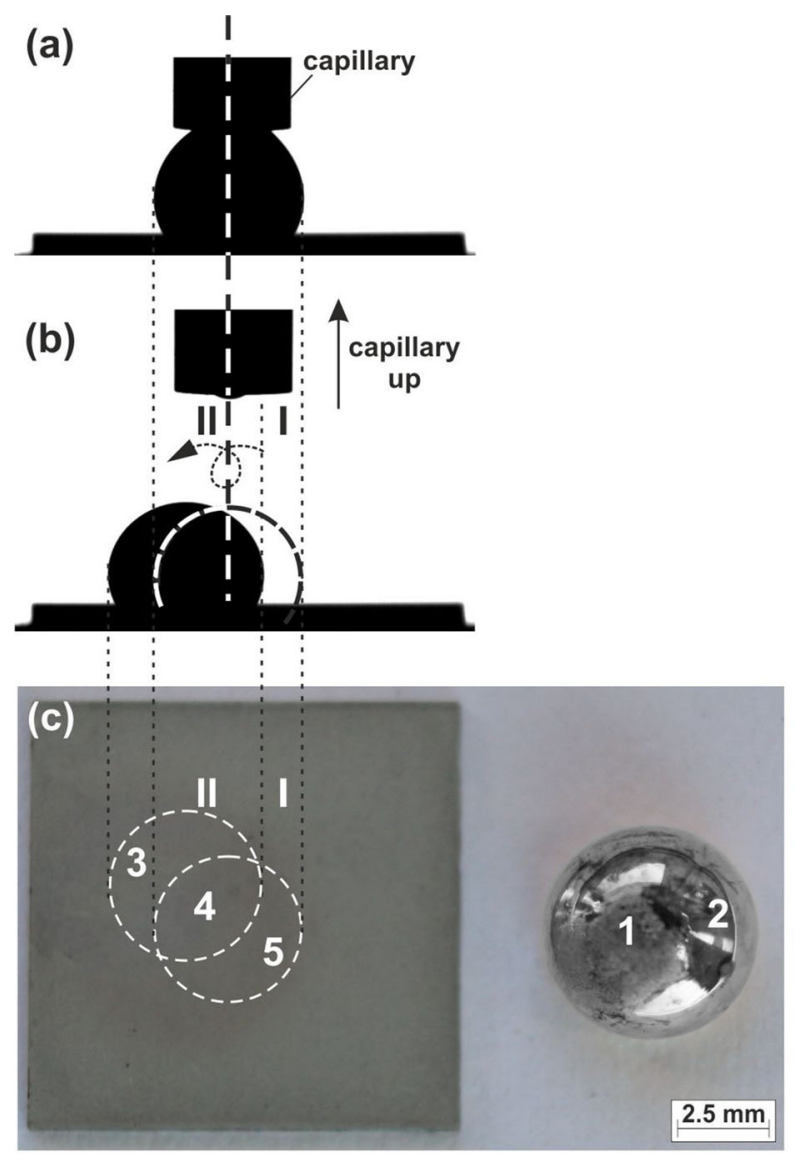
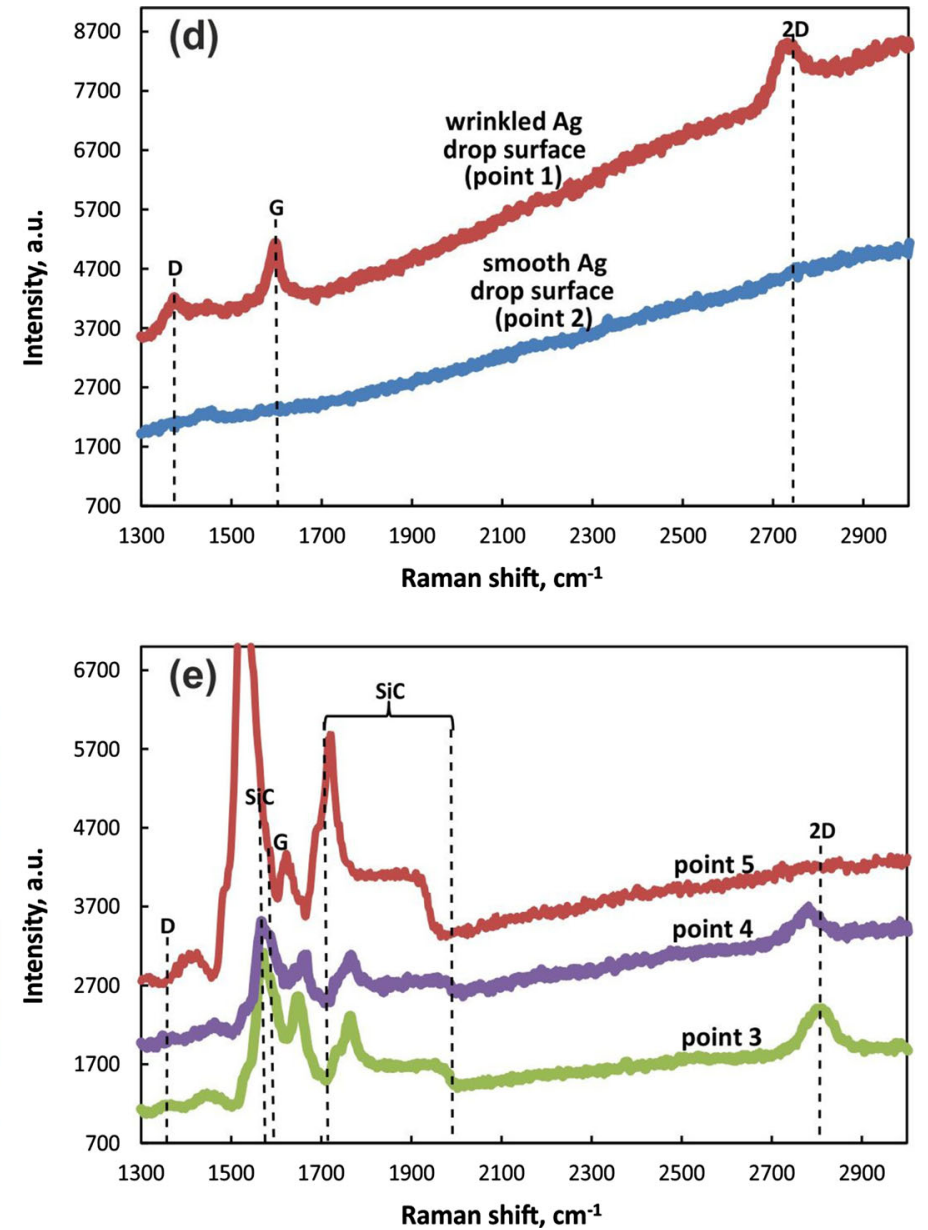

Fig. 8 Raman analyses of the $\mathrm{Ag}$ drop and the $\mathrm{C}_{\mathrm{Gn}} / \mathrm{SiC}$ substrate: (a-c) scheme of the formation of two contact areas of the Ag drop with the substrate, (d) Raman spectra of the drop surface at spots 1 and 2 marked in figure (c); (e) Raman spectra of the substrate at spots 3, 4, 5 marked in figure $(\mathrm{c})$

Table 1 The contact angles formed at $970-1000{ }^{\circ} \mathrm{C}$ with liquid $\mathrm{Ag}$ on different substrates

\begin{tabular}{|c|c|c|c|c|c|c|c|}
\hline \multirow[b]{2}{*}{ Substrate } & \multicolumn{4}{|c|}{ Testing conditions } & \multirow[b]{2}{*}{$\theta,^{\circ}$} & \multirow[b]{2}{*}{ Remarks } & \multirow[b]{2}{*}{ Ref. } \\
\hline & Procedure & Atmosphere, Pa & $T_{\exp },{ }^{\circ} \mathrm{C}$ & Time & & & \\
\hline \multirow[t]{3}{*}{$\mathrm{C}_{\mathrm{Gn}} / \mathrm{SiC}^{\mathrm{sc}}$} & $\mathrm{cp}$ & vac. $2.79 \times 10^{-3}$ & 970 & $0 \min$ & 114 & Gentle deposition, first drop & This work \\
\hline & & & & $11 \mathrm{~min}$ & 114 & & \\
\hline & & & & $12 \mathrm{~min}$ & 113 & Simultaneously squeezing, second drop & \\
\hline \multirow{2}{*}{$\mathrm{C}_{\mathrm{glc}}$} & $\mathrm{ch}$ & vac. $5.00 \times 10^{-3} \mathrm{~Pa}$ & 970 & $15 \mathrm{~min}$ & 106 & - & $(\operatorname{Ref} 23)$ \\
\hline & & vac. $1.00 \times 10^{-4} \mathrm{~Pa}$ & 1000 & $5 \mathrm{~s}$ & 117 & - & (Ref 24) \\
\hline \multirow{6}{*}{$\mathrm{C}_{\mathrm{gr}}$} & $\mathrm{ch}$ & Ar, $p=1.00 \times 10^{5} \mathrm{~Pa}$ & 1000 & $3 \mathrm{~min}$ & 130 & - & $(\operatorname{Ref} 25)$ \\
\hline & $\mathrm{ch}$ & $\mathrm{Ar}, p=1.00 \times 10^{5} \mathrm{~Pa}$ & 1000 & $20 \mathrm{~min}$ & 125 & - & (Ref 26) \\
\hline & $\mathrm{ch}$ & vac. $1.00 \times 10^{-4} \mathrm{~Pa}$ & 1000 & $5 \mathrm{~s}$ & 124 & Polycrystalline & (Ref 24) \\
\hline & $\mathrm{n} / \mathrm{a}$ & $\mathrm{Ar}+10 \% \mathrm{H}_{2}$ & 1000 & $\mathrm{n} / \mathrm{a}$ & 127 & Polycrystalline & $(\operatorname{Ref} 24)$ \\
\hline & $\mathrm{ch}$ & $\mathrm{Ar}$ & 961 & $\mathrm{n} / \mathrm{a}$ & 124 & Monocrystalline & (Ref 27) \\
\hline & $\mathrm{n} / \mathrm{a}$ & $\mathrm{H}_{2}$ & 961 & $\mathrm{n} / \mathrm{a}$ & 157 & Monocrystalline & $(\operatorname{Ref} 24)$ \\
\hline \multirow[t]{3}{*}{$\mathrm{C}_{\mathrm{d}}$} & $\mathrm{ch}$ & $\mathrm{H}_{2}$ & 1000 & $\mathrm{n} / \mathrm{a}$ & 147 & Crystal face (111) & (Ref 28) \\
\hline & & & & & 103 & Crystal face (110) & \\
\hline & & & & & 135 & Crystal face (100) & \\
\hline \multirow[t]{4}{*}{$\mathrm{SiC}$} & $\mathrm{cp}$ & vac. $1.00 \times 10^{-5}$ & 1000 & $30 \mathrm{~min}$ & 148 & Polycrystalline, pressureless-sintered & $(\operatorname{Ref} 29)$ \\
\hline & & $\mathrm{He}$ & 1100 & $0 \mathrm{~min}$ & 145 & Single crystal & $(\operatorname{Ref} 30)$ \\
\hline & & $\mathrm{He}$ & 1100 & $\mathrm{n} / \mathrm{a}$ & 120 & & \\
\hline & & $\mathrm{He}$ & 1200 & $0 \min$ & 65 & & \\
\hline $\mathrm{SiO}_{2}$ & $\mathrm{n} / \mathrm{a}$ & $\mathrm{n} / \mathrm{a}$ & 1100 & $\mathrm{n} / \mathrm{a}$ & 142 & - & $(\operatorname{Ref} 31)$ \\
\hline
\end{tabular}

Legend: $c p$ capillary purification technique combined with non-contact heating, $c h$ contact heating; $\mathrm{C}_{\mathrm{Gn}} / \mathrm{SiC}{ }^{\mathrm{sc}}$, graphene deposited on $\mathrm{SiC}$ single crystal, $C_{g l c}$ glassy-like carbon, $C_{g r}$ graphite, $C_{d}$ diamond 


\begin{tabular}{|c|c|c|c|c|c|c|}
\hline \multirow[b]{2}{*}{$T,{ }^{\circ} \mathrm{C}$} & \multicolumn{6}{|c|}{ Pressure of residual gases, $\mathrm{Pa}$} \\
\hline & $\mathbf{p}_{\mathrm{H} 2}$ & $\mathbf{p}_{\mathrm{H} 2 \mathrm{O}}$ & $\mathbf{p}_{\mathbf{C}}$ & $\mathbf{p}_{\mathrm{CO}+\mathrm{N} 2}$ & $\mathbf{p}_{\mathrm{CO} 2}$ & $p_{\text {total }}$ \\
\hline 25 & $1.34 \times 10^{-6}$ & $2.65 \times 10^{-5}$ & $4.19 \times 10^{-8}$ & $4.30 \times 10^{-7}$ & $6.23 \times 10^{-7}$ & $1.78 \times 10^{-4}$ \\
\hline 200 & $3.04 \times 10^{-6}$ & $3.00 \times 10^{-5}$ & $8.56 \times 10^{-8}$ & $7.27 \times 10^{-7}$ & $1.09 \times 10^{-6}$ & $2.92 \times 10^{-4}$ \\
\hline 400 & $1.27 \times 10^{-5}$ & $4.13 \times 10^{-5}$ & $1.73 \times 10^{-7}$ & $1.15 \times 10^{-6}$ & $2.19 \times 10^{-6}$ & $4.35 \times 10^{-4}$ \\
\hline 600 & $7.66 \times 10^{-5}$ & $5.65 \times 10^{-5}$ & $5.69 \times 10^{-7}$ & $2.00 \times 10^{-6}$ & $1.00 \times 10^{-5}$ & $7.25 \times 10^{-4}$ \\
\hline 800 & $5.47 \times 10^{-5}$ & $6.89 \times 10^{-5}$ & $8.61 \times 10^{-7}$ & $3.80 \times 10^{-6}$ & $1.43 \times 10^{-5}$ & $8.34 \times 10^{-4}$ \\
\hline 970 & $8.30 \times 10^{-5}$ & $8.30 \times 10^{-5}$ & $5.77 \times 10^{-6}$ & $2.45 \times 10^{-5}$ & $8.30 \times 10^{-5}$ & $2.96 \times 10^{-3}$ \\
\hline 1000 & $8.30 \times 10^{-5}$ & $8.30 \times 10^{-5}$ & $5.22 \times 10^{-6}$ & $2.56 \times 10^{-5}$ & $8.30 \times 10^{-5}$ & $2.79 \times 10^{-3}$ \\
\hline $1000^{1}$ & $8.30 \times 10^{-5}$ & $8.30 \times 10^{-5}$ & $4.20 \times 10^{-6}$ & $1.82 \times 10^{-5}$ & $7.72 \times 10^{-5}$ & $2.66 \times 10^{-4}$ \\
\hline $1000^{2}$ & $8.30 \times 10^{-5}$ & $8.30 \times 10^{-5}$ & $4.22 \times 10^{-6}$ & $3.52 \times 10^{-5}$ & $8.30 \times 10^{-5}$ & $2.12 \times 10^{-3}$ \\
\hline
\end{tabular}

Legend: $25-$ before heating, $1000-t=0 \mathrm{~s}$, first drop (start of the test), $1000^{1}-\mathrm{t}=11 \mathrm{~min}$ of the test, $1000^{2}-t=12$ min, second drop spontaneous squeezing, end of the test

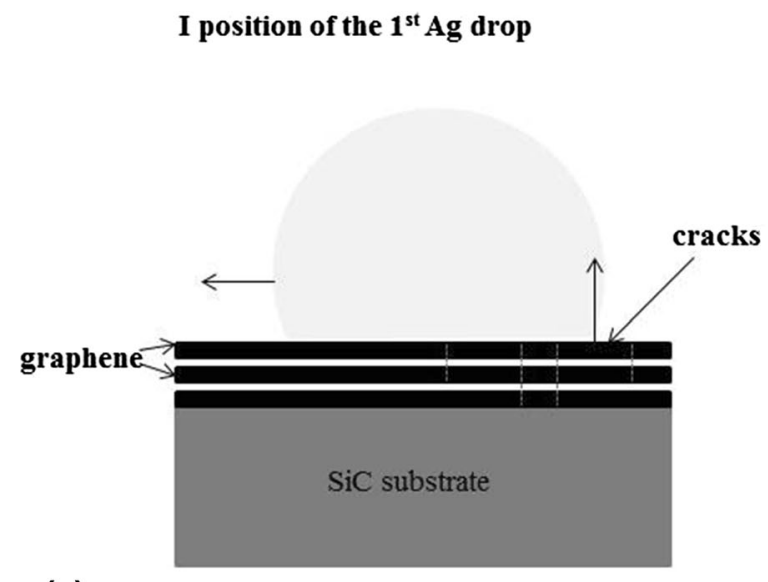

(a)
II position of the $1^{\text {st }} \mathrm{Ag}$ drop

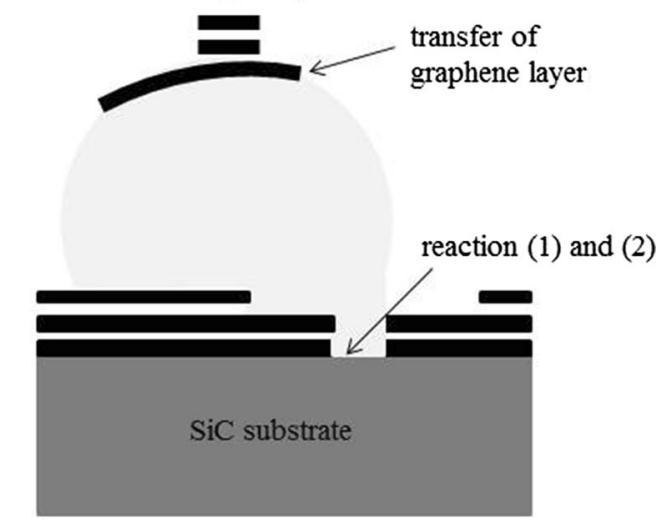

(b)

Fig. 9 Scheme of graphene layer formation on the surface of the Ag drop when the drop is changing its position due to the presence of cracks formed in the layers of graphene (a) and followed by the transfer of graphene fragments to the drop surface (b)

Furthermore, despite the fact that the Si acts as tensioactive element in respect to liquid $\mathrm{Ag}$ and contributes to the wettability improvement of the $\mathrm{Ag} / \mathrm{SiC}$ system (Ref 31 ), any decrease in the contact angle was not observed in this study. Most probably, there are two reasons: (1) the concentration of Si was negligible, or (2) the occurrence of a reaction between liquid silver and $\mathrm{SiC}$ in the discontinuities of graphene layer was quickly stopped by forming of graphite layer according to the chemical reaction (2). Therefore, we conclude that the presence of discontinuities in graphene layer has no influence on investigations of wetting transparency of graphene.

The existence of large area of graphene segregated at the drop surface (approximately 20 times larger than the area with voids generated at the bottom Ag drop surface) suggests that under the conditions of our experiment, a similar phenomenon can occur: (1) transfer of a graphene layer; (2) dissolution of graphene layer due to dissolution of carbon in liquid Ag; (3) growth of a layer of secondary graphene on liquid Ag drop surface by a combination of segregation, nucleation and rearrangement of carbon atoms at the $\mathrm{Ag}$ surface as already observed by Sobczak et al. (Ref 18).

The transfer of a graphene layer from the interface to the surface of the drop is schematically presented in Fig. 9. During

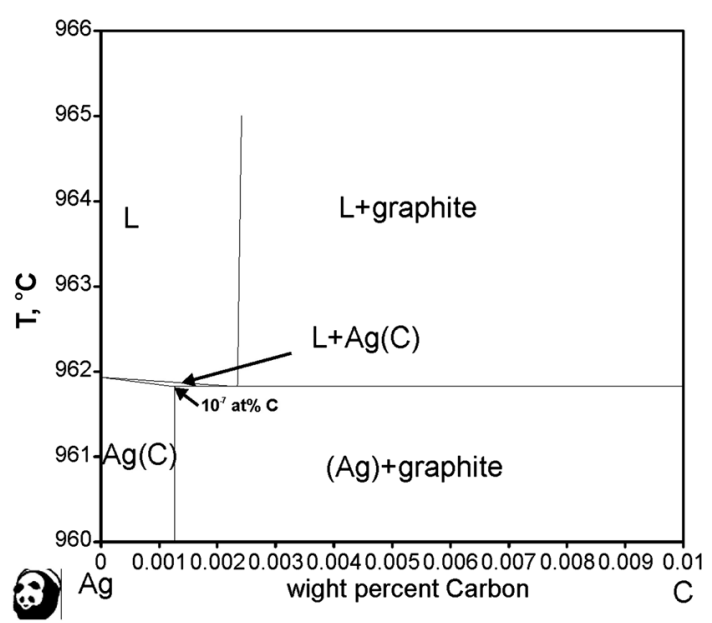

Fig. 10 Ag-rich corner of the Ag-C phase diagram calculated using PanDat thermodynamic software

drop movements, the outer layer/layers of graphene was/were peeled off (basically driven by strong adhesion between $\mathrm{Ag}$ drop and $\mathrm{C}_{\mathrm{Gn}} / \mathrm{SiC}$ ) (Fig. 9a) exposing the surface of uncoated 
SiC (Fig. 9b) and enabled liquid Ag to be in direct chemical interaction with the substrate $(\mathrm{SiC})$.

The dissolution of graphene layer due to carbon dissolution in liquid Ag and growth of a layer of secondary graphene on liquid Ag drop surface can be explained based on Ag-C phase diagram (Fig. 10).

As suggested by Amini and Abbaschian (Ref 34), the presence of uniform large area of bilayered graphene on the $\mathrm{Ag}$ drop surface, revealed by Raman spectra, could be obtained by the growth of secondary graphene sheets, owing to the freshly produced $\mathrm{C}$ and $\mathrm{Si}$ (by the dissolution of $\mathrm{SiC}$ ) at the interface, followed by $\mathrm{C}$ nucleation-reorganization at the border of the graphene detached and transferred from the interface. Moreover, the presence of the large part of the $\mathrm{C}$ precipitates in the area of the graphene flakes at the surface of the solidified $\mathrm{Ag}$ drop indicates that $\mathrm{C}$ dissolved in Ag diffused mainly in the direction of this area. As a further confirmation of $\mathrm{SiC}$ dissolution by liquid $\mathrm{Ag}$, on the surface of the drop, as already mentioned, the presence of $\mathrm{Si}$ was also detected. As described by Weber (Ref 35 ). Ag forms with $\mathrm{Si}$ at solid state a single eutectic at Si 11 at.\% with a solidifying $T=835{ }^{\circ} \mathrm{C}$. Therefore, one may expect that at the test temperature $T=970{ }^{\circ} \mathrm{C}$, the dissolution of $\mathrm{SiC}$ occurred immediately after the $\mathrm{Ag} / \mathrm{SiC}$ was created.

The same mechanism was used to explain the results obtained for the already cited $\mathrm{Cu}, \mathrm{Ni}$ (Ref 8). In addition, Kula et al. (Ref 36) proved that on the surface of liquid metal, the effect of self-arrangement of the formed secondary graphene "areas" at the top of the metal drop (flakes) can move on the drop surface, rotate and join other formed graphene layers, giving as a result, after solidification an area of graphene larger than the original one. Unluckily, to now, the production of graphene layers by solid carbon dissolution process, detected at the top of pure liquid Ag, is reported only by Tanaka and Ijima in their work (Ref 37) where is clearly evident, at least, the role of liquid Ag to catalyze the production of similar graphene layers evolving later as nanotubes.

\section{Summary}

Wetting behavior and interfacial phenomena that occur in liquid $\mathrm{Ag} / \mathrm{C}_{\mathrm{Gn}} / \mathrm{SiC}$ system have been investigated by the dispensed drop method at $T=970{ }^{\circ} \mathrm{C}$ under vacuum. Exhaustive surface and microstructural characterization (by SEM/EDS and SPM/Raman techniques) have been done before and after high-temperature wetting tests. By analyzing the contact angle behavior as a function of time, after its deposition onto the graphene-coated $\mathrm{SiC}$ substrate, the Ag drop showed a contact angle value of $114^{\circ}$ and this value was preserved also when additional liquid Ag was squeezed on the first drop. Surface characterization of the drop surface after wettability tests evidenced the presence of 2D-C (graphene) and Si at the top of solidified Ag drop suggesting that a chemical interaction occurred at the interface. In addition, at the interface, destruction of graphene layer was detected and on the uncoated $\mathrm{SiC}$ surface, voids were revealed which were probably due to chemical reactions with gas as products. Local dissolution of $\mathrm{C}$ and $\mathrm{Si}$ into liquid $\mathrm{Ag}$ resulting as reaction products of $\mathrm{SiC}$ decomposition by liquid $\mathrm{Ag}$ is evidenced by the presence of these two constituents at the top of the solidified drop. In addition, transfer of the fragmented graphene layer and its reorganization (by segregation, nucleation and growth) at the Ag surface during drop solidification was observed.

With a view to offer new insights designing and to properly address the manufacture of tailored graphene-metal composites or in general in joining dissimilar graphene-coated materials by liquid-assisted methods, a strong adhesion at liquid $\mathrm{Ag} / \mathrm{C}_{\mathrm{Gn}}$ interface has been observed even if locally, at high temperatures. The strong adhesion is one of the main characteristics of wetting transparency of graphene. Despite of this fact, it is clearly evident in this case, the main chemical interactions were given by the locally produced discontinuities, which could be in turn owed to thermomechanical stresses, local weak $\mathrm{C}_{\mathrm{Gn}} / \mathrm{SiC}$ adhesion, or already present defect in the graphene layers, etc.

\section{Acknowledgments}

The test has been performed using experimental facility developed by the Foundry Research Institute. The authors are grateful to the Foundry Research Institute and the National Centre for Research and Development for financial support (Project No. GRAF-TECH/NCBR/10/29/2013 "Novel graphene reinforced metal matrix composites for power and electronic industry"). D. Giuranno appreciates the National Science Centre Poland for financial support UMO-2016/23/P/ST8/01916, SIC-WIN: Reactivity of Silicon-alloy/C-material system: Wetting versus Infiltration (NCN, POLONEZ-3, 2017-2018). The authors acknowledge Eng. Gabriela Zaczyk for technical assistance with SEM microscopy characterization. The authors acknowledge Ph.D. Włodzimierz Strupiński for graphene materials.

\section{Open Access}

This article is distributed under the terms of the Creative Commons Attribution 4.0 International License (http://creativecommons.org/ licenses/by/4.0/), which permits unrestricted use, distribution, and reproduction in any medium, provided you give appropriate credit to the original author(s) and the source, provide a link to the Creative Commons license, and indicate if changes were made.

\section{References}

1. H.G.P. Kumar and M.A. Xavior, Graphene Reinforced Metal Matrix Composite (GRMMC), Procedia Eng., 2014, 97, p 1033

2. W. Yang, Q. Zhao, L. Xin, J. Qiao, J. Zou, P. Shao, Z. Yu, Q. Zhang, and G. Wu, Microstructure and Mechanical Properties of Graphene Nanoplates Reinforced Pure Al Matrix Composites Prepared by Pressure Infiltration Method, J. Alloys Compd., 2018, 732, p 748-758

3. F. Chen, J. Ying, Y. Wang, S. Du, Z. Liu, and Q. Huang, Effect of Graphene Content on the Microstructure and Properties of Copper Matrix Composites, Carbon, 2016, 96, p 836

4. J. Li and C.-Y. Liu, Ag/Graphene Heterostructures: Synthesis, Characterization and Optical Properties, Eur. Inorg. Chem., 2010, 2010, p 1244-1248. https://doi.org/10.1002/ejic.200901048

5. G.A. López and E.J. Mittemeijer, The Solubility of $\mathrm{C}$ in Solid $\mathrm{Cu}$, Scripta Mater, 2004, 51, p 1

6. I. Karakaya and W.T. Thompson, The Ag-C (Silver-Carbon) System, Bull. Alloy Phase Diagr., 1988, 9(3), p 226

7. S. Amini, J. Garay, G. Liu, A.A. Balandin, and R. Abbaschian, Growth of Large-Area Graphene Film from Metal-Carbon Melts, J. Appl. Phys., 2010, 108, p 094321

8. S. Amini, H. Kalaantari, J. Garay, A.A. Balandin, and R. Abbaschian, Growth of Graphene and Graphite Nanocrystals from a Molten Phase, J. Mater. Sci., 2011, 46, p 6255 
9. S.Y. Cho, M.-S. Kim, M. Kim, H.-M. Kim, D.-J. Lee, S.-H. Lee, and K.-B. Kim, Self-Assembly and Continous Growth of Hexagonal Graphene Flakes On Liquid Cu, Nanoscale, 2015, 7, p 12820-12827

10. J. Wang, L. Chen, N. Wu, Z. Kong, M. Zeng, and T. Zhang, Uniform Graphene on Liquid Metal by Chemical Vapour Deposition at Reduced Temperature, Carbon, 2016, 96, p 799

11. G. Ding, Y. Zhu, S. Wang, Q. Gong, L. Sun, T. Wu, X. Xie, and M. Jiang, Chemical Vapor Deposition of Graphene on Liquid Metal Catalysts, Carbon, 2013, 53, p 321-326

12. J. Rafiee, M.A. Rafiee, Z.Z. Yu, and N. Koratkar, Superhydrophobic to Superhydrophilic Wetting Control in Graphene Films, Adv. Mater. 2010, 22, p 2151

13. J. Rafiee, X. Mi, H. Gullapalli, A.V. Thomas, F. Yavari, Y. Shi, P.M. Ajayan, and N.A. Koratkar, Wetting Transparency of Graphene, Nat. Mater, 2012, 11, p 217

14. N. Sobczak, J.J. Sobczak, A. Kudyba, M. Homa, G. Bruzda, M. Grobelny, M. Kalisz, K. Strobl, R. Singhal, and M. Monville, Wetting Transparency of Graphene Deposited on Copper in Contact with Liquid Tin, Trans. Foundry Res. Inst. LIV, 2014, 3, p 3

15. M. Homa, N. Sobczak, J.J. Sobczak, A. Kudyba, G. Bruzda, R. Nowak, D. Giuranno, K. Pietrzak, M. Chmielewski, and W. Strupiński, Interaction Between Graphene-Coated SiC Single Crystal and Liquid Copper, J. Mater. Perform., 2018, https://doi.org/10.1007/s11665-0183340-8

16. W. Strupinski, K. Grodecki, A. Wysmolek, R. Stepniewski, T. Szkopek, P.E. Gaskell, A. Grüneis, D. Haberer, R. Bozek, J. Krupka, and J.M. Baranowski, Graphene Epitaxy by Chemical Vapor Deposition on SiC, Nanoletters, 2011, 11, p 1786-1791

17. N. Sobczak, R. Nowak, W. Radziwill, J. Budzioch, and A. Glenz, Experimental Complex for Investigations of High-Temperature Behaviour of Molten Metals in Contact with Refractory Materials, Mater. Sci. Eng. A, 2008, 495, p 43

18. N. Sobczak, A. Kudyba, R. Nowak, W. Radziwill, and K. Pietrzak, Factors Affecting Wettability and Bond Strength of Solder Joint Couples, Pure Appl. Chem., 2007, 79(10), p 1755

19. L. Liggieri and A. Passerone, An Automatic Technique for Measuring the Surface Tension of Liquid Metals, High Temp. Technol., 1989, 7, p 80

20. ASTRA Reference Book, IENI, Report Oct. 2007

21. K. Gajewski, D. Kopiec, M. Moczała, A. Piotrowicz, M. Zielony, G. Wielgoszewski, T. Gotszalk, and W. Strupiński, Scanning Probe Microscopy Investigations of the Electrical Properties of Chemical Vapor Deposited Graphene Grown on a 6H-SiC Substrate, Micron, 2015, 68, p 17
22. K. Grodecki, Raman Spectroscopy of Graphene, Electron. Mater, 2013, 41(1), p 47

23. D. Wójcik-Grzybek, K. Frydman, N. Sobczak, and R. Nowak, Wpływ reaktywnych dodatków stopowych na zwilżalność w układzie Ag/C, Inżynieria Materiałowa, 2010, 2, p 104

24. R.C. Hula, Ch. Edtmaier, M. Holzweber, H. Hutter, and Ch. Eisenmenger- Sittner, The Wetting Behaviour of Silver on Carbon, Pure and Carburized Nickel, Cobalt and Molybdenum Substrates, Appl. Surf. Sci., 2010, 156, p 4697

25. Z. Weltsch and A. Lovas, Wettability of Ceramic Substrates by Silver Based Alloys, Acta Phys. Pol., A, 2013, 124(1), p 78

26. Z. Weltsch, A. Lovas, J. Takács, Á. Cziráki, A. Toth, and G. Kaptay, Measurement and Modelling of the Wettability of Graphite by a Silvertin (Ag-Sn) Liquid Alloy, Appl. Surf. Sci., 2013, 268, p 52

27. J. Lee, T. Tanaka, K. Seo, N. Hirai, J.G. Lee, and K. Mori, Wetting of $\mathrm{Au}$ and $\mathrm{Ag}$ Particles on Monocrystalline Graphite Substrates, Rare Met., 2006, 25(5), p 469

28. P. Shen, H. Fuji, and K. Nogi, Effect of Substrate Crystallographic Orientation on Wettability and Adhesion in Several Representative Systems, J. Mater. Process. Tech., 2004, 155-156, p 1256

29. M. Shimbo, M. Naka, and I. Okamoto, Wettability of Silicon Carbide by Aluminium, Copper and Silver, J. Mater. Sci. Lett., 1989, 8, p 663

30. S. Kalogeropoulou, C. Rodo, and N. Eustathopoulos, Mechanisms of Reactive Wetting: the Wetting to Non-Wetting Case, Scripta Mater, 1999, 41(7), p 723

31. J.G. Li, Wettability of Silicon Carbide by Liquid Silver and Binary Silver-Silicon Alloy, Mater. Lett., 1994, 18, p 291

32. C. Rodo, S. Kalogeropoulou, and N. Eustathopoulos, Bonding and Wetting in Non-Reactive Metal/SiC Systems: Weak or Strong Interfaces, Mater. Sci. Eng. A, 2000, 276, p 195

33. J. Narciso, E. Louis, C. Garcia-Cordovilla, Pressure infiltration of packed $\mathrm{SiC}$ and alumina particulates by liquid silver with dissolved oxygen, Proceedings of International Conference High Temperature Capillarity Edited by N. Eustathopoulos and N. Sobczak (1997) 283

34. S. Amini and R. Abbaschian, Nucleation and Growth Kinetics of Graphene Layers from a Molten Phase, Carbon, 2013, 51, p 110

35. L. Weber, Equilibrium Solid Solubility of Silicon in Silver, Metall. Mater. Trans. A, 2002, 33, p 1145

36. P. Kula, W. Szymanski, Ł. Kolodziejczyk, R. Atraszkiwicz, K. Dybowski, J. Grabarczyk, R. Pietrasik, P. Niedzielski, Ł. Kaczmarek, and M. Clapa, High Strength Metallurgical Graphene-Mechanism of Growth and Properties, Arch. Metall. Mater., 2015, 60(4), p 2532-2541

37. K. Tanaka and S. Ijima, Carbon Nanotube and Graphene, Elsevier, Amsterdam, 2014, p 9 